\title{
Study of Large-Scale Aluminium-Doped Zinc Oxide Ceramic Targets Prepared by Slip Casting
}

\author{
Ling-yun Han and Yong-chun Shu \\ TEDA Applied Physics Institute, Nankai University, Tianjin 300457, China \\ Correspondence should be addressed to Yong-chun Shu; shuyc@nankai.edu.cn
}

Received 28 December 2015; Revised 7 March 2016; Accepted 7 March 2016

Academic Editor: Pavel Lejcek

Copyright ( 2016 L.-y. Han and Y.-c. Shu. This is an open access article distributed under the Creative Commons Attribution License, which permits unrestricted use, distribution, and reproduction in any medium, provided the original work is properly cited.

\begin{abstract}
Aluminium-doped zinc oxide (AZO) ceramic green compacts at a size of $170 \times 340 \times 17 \mathrm{~mm}$ have been prepared by slip casting. An AZO slurry with good fluidity and viscosity was obtained when $1.2 \mathrm{wt} \%$ of dispersant was added, which indicates that the slurry prepared with micrometre particles is more suitable for slip casting. The densification and electrical properties of the AZO targets prepared by particles with different sizes were investigated after sintering from 1380 to $1460^{\circ} \mathrm{C}$. The results showed that the relative density of the AZO target prepared with $45 \mathrm{~nm}$ particles could reach nearly $98 \%$ at $1380^{\circ} \mathrm{C}$; the resistivity of the AZO target prepared with nanometre particles could be as low as $1.6 \times 10^{-3} \Omega \cdot \mathrm{cm}$ at $1400^{\circ} \mathrm{C}$; and the average transmittance of the AZO film prepared with nanometre particles could reach a maximum value of $93.73 \%$ in the visible region at $250 \mathrm{~W}$. In this study, the correlation between the density, resistivity, and grain growth of AZO ceramic green compacts was studied.
\end{abstract}

\section{Introduction}

Zinc oxide $(\mathrm{ZnO})$ is regarded as a new type of n-type semiconductor material with a band gap of $3.36 \mathrm{eV}$. $\mathrm{ZnO}$ based materials are widely used for optoelectronic devices, solar cells, light emitting diodes, and thin film transistors because of their electrical and optical properties. A number of studies have investigated dopants in $\mathrm{ZnO}$, such as $\mathrm{Bi}, \mathrm{Mn}$, $\mathrm{Cu}, \mathrm{Sb}, \mathrm{Pr}, \mathrm{Cr}$, and $\mathrm{Al}[1-8]$. Because of their low resistivity $\left(<10^{-3} \Omega \cdot \mathrm{cm}\right)$, high transmittance $(>80 \%)$, and low cost, aluminium-doped zinc oxide (AZO) films have been studied as potential new transparent conductive oxide films $[9,10]$.

There are several methods of preparing AZO films, including magnetron sputtering, pulsed laser deposition (PLD), sol-gel, and chemical vapour deposition. However, only magnetron sputtering has been used to prepare largescale films with high quality because of its high deposition rate and low deposition temperature [11-14]. Because sputtering is the main method of preparing AZO films, fabricating the sputtering target has become the most important step of the method [15].

The main methods used to prepare sputtering targets in industry include pressureless sintering after mould pressing, cold isostatic pressing (CIP), hot pressed sintering, and hot isostatic pressing (HIP). However, cracks always occur when these methods are used to fabricate large-sized ceramic targets. Thus, slip casting has become one of the most useful methods in the ceramic industry of preparing homogeneous and dense green bodies with large sizes and complex shapes [16-18].

In the slip casting process, particle dispersion is the main factor affecting the viscosity and homogeneity of the slurry. Because of the small size effect, surface effect, and quantum size effect, nanometre particles may significantly impact the preparation of ceramics, including the sintering temperature, holding time, and density. A number of studies have reported on the sintering and grain growth of $\mathrm{ZnO}$ and $\mathrm{Al}$-doped $\mathrm{ZnO}$, including the studies of Roy et al. [19] and Han et al. [20]. However, the preparation of large-sized AZO targets for the industry has rarely been studied.

In this paper, we studied the effect of dispersant concentration on AZO slurries for slip casting prepared using different particle sizes and explored the effect of nanometre particles on the density, microstructure, and electrical properties of the AZO target. The transmittance of AZO films deposited at different sputtering powers was also investigated. 


\section{Experimental}

Commercial $\mathrm{ZnO}$ and $\mathrm{Al}_{2} \mathrm{O}_{3}$ powders with $99.99 \%$ purity and average particle sizes of 45,120,230, and $510 \mathrm{~nm}$ were used. Ammonium polyacrylate and Arabic gum were used as the dispersant and binder, respectively. All of the chemical reagents used in the experiments were analytically pure. Dispersant $(0.2-2.0 \mathrm{wt} \%)$ and binder $(0.8 \mathrm{wt} \%)$ were first added to distilled water to prepare an aqueous solution, and the amounts of the dispersant and binder used in the experiment were based on the dry powder weight. Subsequently, $2 \mathrm{wt} \%$ $\mathrm{Al}_{2} \mathrm{O}_{3}$ was mixed with $98 \mathrm{wt} \% \mathrm{ZnO}$ powders and added to the aqueous solution. After ball milling with $\mathrm{Al}_{2} \mathrm{O}_{3}$ milling balls in a vacuum for $12 \mathrm{~h}$, white $\mathrm{Al}_{2} \mathrm{O}_{3}$-doped $\mathrm{ZnO}(\mathrm{AZO})$ slurries with good fluidity and viscosity could be obtained. The ball to powder ratio was $2: 1$. The prepared slurries were poured gently into the plaster mould and placed at room temperature for 24 hours. The solid slurries then were dried at $80^{\circ} \mathrm{C}$ for 1 week to remove the water. After thermal treatment at $500^{\circ} \mathrm{C}$ for 48 hours, AZO green compacts at a size of $170 \times 340 \times$ $17 \mathrm{~mm}$ were finally obtained.

The green compacts were heated at $1^{\circ} \mathrm{C} / \mathrm{min}$ to the sintering temperatures $\left(1380,1400,1420,1440\right.$, and $\left.1460^{\circ} \mathrm{C}\right)$ for $2 \mathrm{~h}$ and cooled to room temperature in the furnace.

The AZO films were deposited on the glass substrates using the sintered compacts by magnetron sputtering at different working powers $(150-300 \mathrm{~W})$. The thickness of the film was $300 \mathrm{~nm}$, and the working pressure was $1.0 \times 10^{-2}$ torr.

The viscosity of the slurries was measured by a digital rotational viscometer (NDJ-5S, Jingtian, Shanghai, China) at a shear rate of $6.3 \mathrm{~s}^{-1}$. The sintered densities of these samples were measured by Archimedes' method in distilled water. The theoretical densities of $\mathrm{ZnO}$ and $\mathrm{Al}_{2} \mathrm{O}_{3}$ were determined to be 5.6 and $3.98 \mathrm{~g} / \mathrm{cm}^{3}$, respectively. Thus, the theoretical density of AZO was calculated to be $5.56 \mathrm{~g} / \mathrm{cm}^{3}$. The resistivity of the sintered targets was tested by a four-point probe method (ST2258A, Jingge Electronic Co., Suzhou, China); the microstructure of the fractures was tested using a scanning electron microscope (1530vp, Leo Co., Germany); and the optical transmission spectra were obtained using a UV-vis spectrophotometer (V570, JASCO, Japan).

\section{Results and Discussion}

3.1. Viscosity. In general, a lower slurry viscosity is beneficial for slip casting. Figure 1 shows the effect of dispersant concentration on the viscosity of AZO slurries with different particle sizes. The viscosity was higher because of the absence of dispersant and decreased as the dispersant concentration rose from 0.2 to $1.2 \mathrm{wt} \%$. When the amount of dispersant exceeded $1.2 \mathrm{wt} \%$, the viscosity of slurries exhibited nearly constant value. This result indicates that the addition of $1.2 \mathrm{wt} \%$ of the dispersant is the optimum concentration. The main reason for this trend was that when the amount of dispersant was adequate to cover the particle surface, the dispersant worked as an electrolyte, thus increasing the repulsive electrostatic force, which leads to the separation of particles and decreased viscosity [21]. However, the viscosity of the slurry prepared with smaller particles was higher, suggesting that the slurry

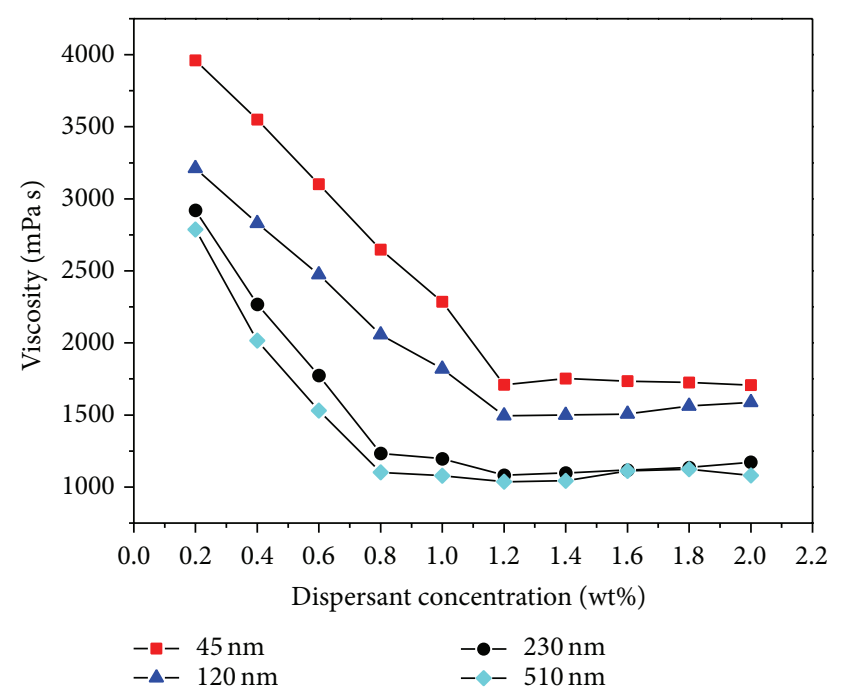

FIGURE 1: Effect of dispersant concentration on the viscosity of AZO slurries with different particle sizes of $45,120,230$, and $510 \mathrm{~nm}$.

TABLE 1: Relative densities of AZO green compacts.

\begin{tabular}{lc}
\hline Sample & Density (\%) \\
\hline A & 61.5 \\
B & 60.6 \\
C & 58.9 \\
D & 58.6 \\
\hline
\end{tabular}

with micrometre particles was more suitable for slip casting, which may have been caused by the small size effect and the surface effect of the nanoparticles. Aggregation of the particles reduced the surface in contact with the dispersant, which impaired the effect of the dispersant as an electrolyte.

3.2. Densification and Microstructural Coarsening. Table 1 reveals the relative densities of AZO green compacts prepared in different particle sizes $(45-510 \mathrm{~nm})$ before sintering. The densities changed slightly from $61.5 \%$ to $58.6 \%$ with the increase of particle sizes. Figure 2 shows the fracture morphology of AZO green compacts prepared in different particle sizes. What we could see in pictures is the particle packing of $\mathrm{ZnO}$ and $\mathrm{Al}_{2} \mathrm{O}_{3}$ powders. The particles in nanometre size aggregated closer than that in micrometre size due to the small size effect and the surface effect of the nanoparticles. The pores of green compact in nanoparticles were small and rare. With the increase of particle sizes from 45 to $510 \mathrm{~nm}$, the number and size of pores in green compacts also increased. It may be because the effect of flocculation in slurries prepared with micrometre particles inhibited the particle movement, resulting in the pore expansion in particle packing process. The green densities then decreased with the pore expansion.

Figure 3 shows the relative densities of AZO targets sintered at different temperatures of 1380, 1400, 1420, 1440, and $1460^{\circ} \mathrm{C}$. Unlike the green compacts, the sintered densities of different samples decreased markedly with increasing particle size at $1380^{\circ} \mathrm{C}$. The relative density of $45 \mathrm{~nm}$ sample 


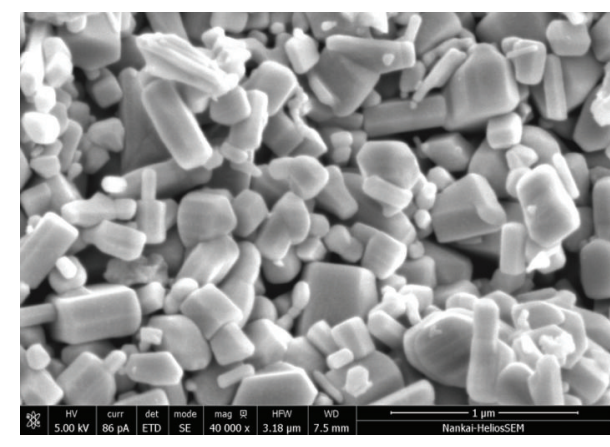

(a)

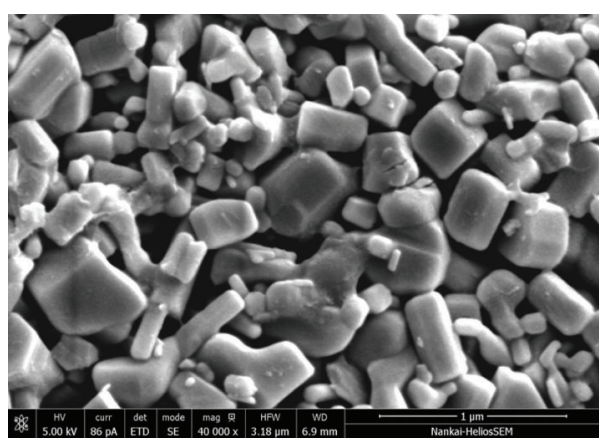

(c)

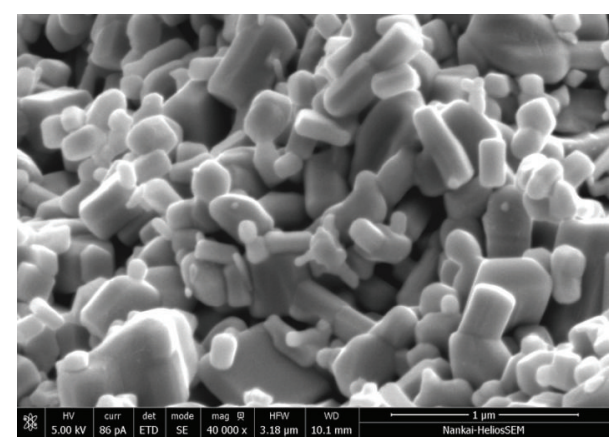

(b)

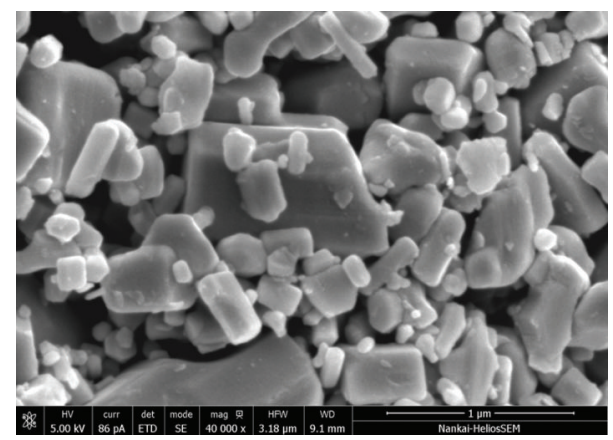

(d)

FIGURE 2: Fracture morphology of AZO green compacts prepared in different particle sizes ((a) $45 \mathrm{~nm}$, (b) $120 \mathrm{~nm}$, (c) $230 \mathrm{~nm}$, and (d) $510 \mathrm{~nm})$.

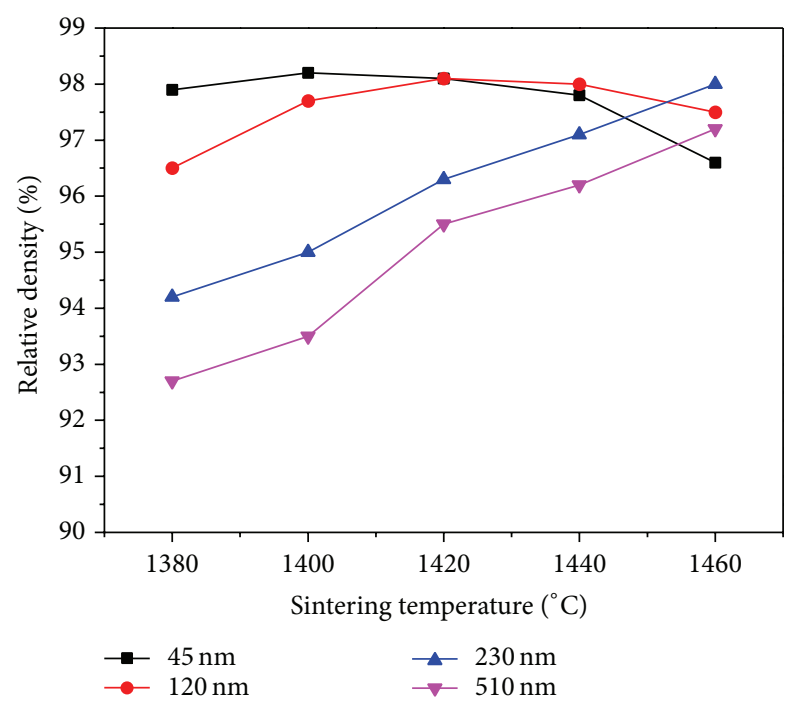

FIGURE 3: Relative densities of AZO targets sintered at temperatures of $1380,1400,1420,1440$, and $1460^{\circ} \mathrm{C}$.

could reach $98 \%$, but it only reached $92.7 \%$ for the $510 \mathrm{~nm}$ sample. The big gap in densities for samples in different particle sizes decreased with increasing sintering temperature. The relativity densities of 230 and $510 \mathrm{~nm}$ samples increased with increasing sintering temperature from $1380^{\circ} \mathrm{C}$ to $1460^{\circ} \mathrm{C}$, while the relative densities of 45 and $120 \mathrm{~nm}$ samples decreased from $97.8 \%$ and $98 \%$ to $96.5 \%$ and $97.5 \%$, respectively, with the sintering temperature increased from $1440^{\circ} \mathrm{C}$ to $1460^{\circ} \mathrm{C}$.

The main reason for the densification of target in nanometre might be the surface effect of the nanoparticles. The densification process was related to the evolution of pores [22]. Figure 4 presents SEM micrographs of the AZO targets prepared with $45 \mathrm{~nm}$ particles sintered at (a) $1380^{\circ} \mathrm{C}$, (b) $1400^{\circ} \mathrm{C}$, (c) $1420^{\circ} \mathrm{C}$, or (d) $1460^{\circ} \mathrm{C}$. It shows the grain size increased with the rise of sintering temperature and the evolution of pores inside the target. As shown in Figure 4(a), the grain size was only $8 \mu \mathrm{m}$ at $1380^{\circ} \mathrm{C}$, and a number of small pores were observed at the grain boundary. It was at initial stage for the sintering process; the driving force for sintering was low. Because of the high surface active energy, the particles in nanometre aggregated faster than those in micrometre, resulting in the high density $(97.9 \%)$ at a low sintering temperature $\left(1380^{\circ} \mathrm{C}\right)$. Figure $4(\mathrm{~b})$ reveals the appearance of large-sized pores accompanied with the disappearance of small pores when the sintering temperature reached to $1400^{\circ} \mathrm{C}$. The number of pores in Figure $4(\mathrm{c})$ obviously decreased, and the small pores nearly vanished. It is because the small pores merged into big ones with the particles aggregation. The density increased with the reduction of small pores in the target. The grain size of the sample sintered at $1420^{\circ} \mathrm{C}$ increased to $22 \mu \mathrm{m}$. When the sintering temperature increased to $1460^{\circ} \mathrm{C}$, it was at late stage for the sintering process. The surface energy decreased with the growth of nanoparticles, thus slowing down the aggregation process of the particles. The gap in densities for samples in 


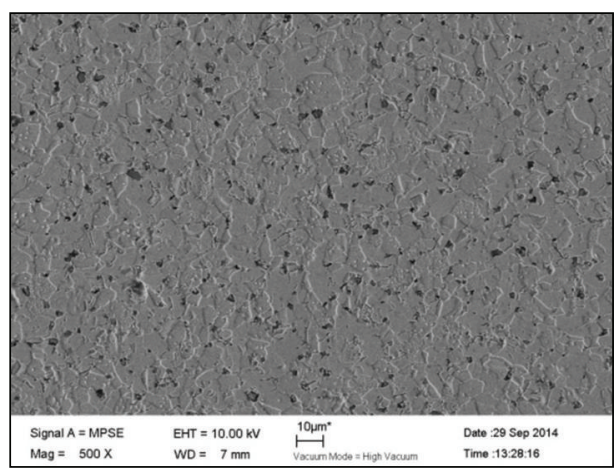

(a) $1380^{\circ} \mathrm{C}$

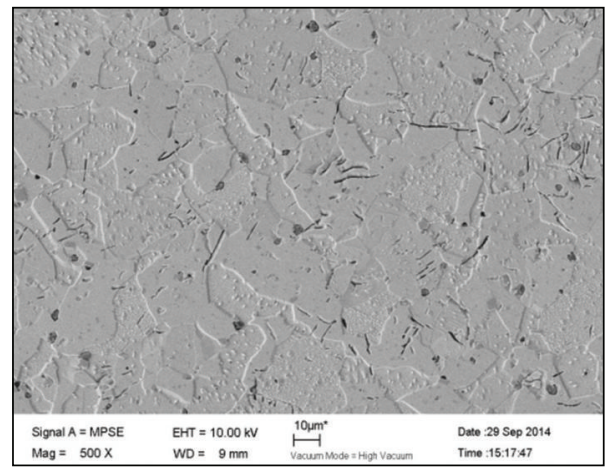

(c) $1420^{\circ} \mathrm{C}$

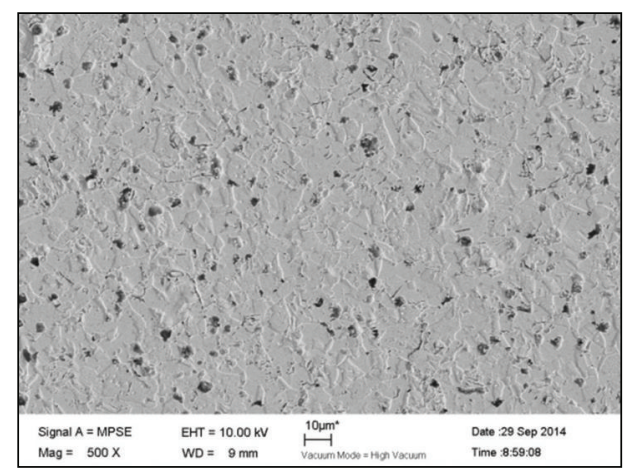

(b) $1400^{\circ} \mathrm{C}$

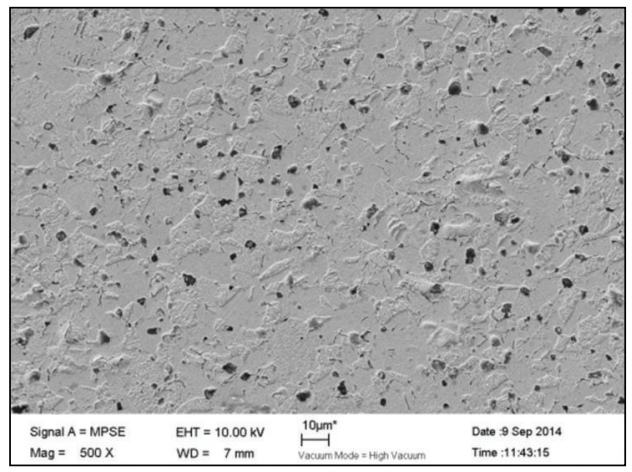

(d) $1460^{\circ} \mathrm{C}$

FIGURE 4: SEM micrographs of AZO targets sintered at (a) $1380^{\circ} \mathrm{C}$, (b) $1400^{\circ} \mathrm{C}$, (c) $1420^{\circ} \mathrm{C}$, and (d) $1460^{\circ} \mathrm{C}$.

different particle sizes decreased. As shown in Figure 4(d), there are a large number of big-sized pores shown inside the target. With the sintering temperature increased, the vapour pressure inside the closed pores became higher than the driving force for densification, which led to the expansion of pores and decreased density. The grain size reached to $30 \mu \mathrm{m}$.

3.3. Resistivity. As shown in Figure 5, the resistivity of the $510 \mathrm{~nm}$ sample at $1380^{\circ} \mathrm{C}$ was the highest at $6.5 \times 10^{-3} \Omega \cdot \mathrm{cm}$, whereas that of the $45 \mathrm{~nm}$ sample was only $1.8 \times 10^{-3} \Omega \cdot \mathrm{cm}$. These results indicate that a huge reduction in the resistivity of the AZO targets occurred from micrometre- to nanometre-sized particles. With increasing sintering temperature, the resistivity of the different samples decreased to a value of approximately $2.0 \times 10^{-3} \Omega \cdot \mathrm{cm}$ at $1440^{\circ} \mathrm{C}$. With further sintering, the resistivity values of the 45 and $120 \mathrm{~nm}$ samples were raised to $2.5 \times 10^{-3}$ and $2.4 \times 10^{-3} \Omega \cdot \mathrm{cm}$, respectively, whereas the values of the 230 and $510 \mathrm{~nm}$ samples decreased to $1.9 \times 10^{-3}$ and $2 \times 10^{-3} \Omega \cdot \mathrm{cm}$, respectively.

A comparison of Figure 3 with Figure 5 shows that the change between the density and resistivity of the AZO targets prepared with different particle sizes was similar. The resistivity decreased with increases in density primarily because the grain growth reduced the number of pores with increases in density at the grain boundary. The increased density and changes in the pores reduced the scanning of electrons by the pores in the target, thus resulting in the fast

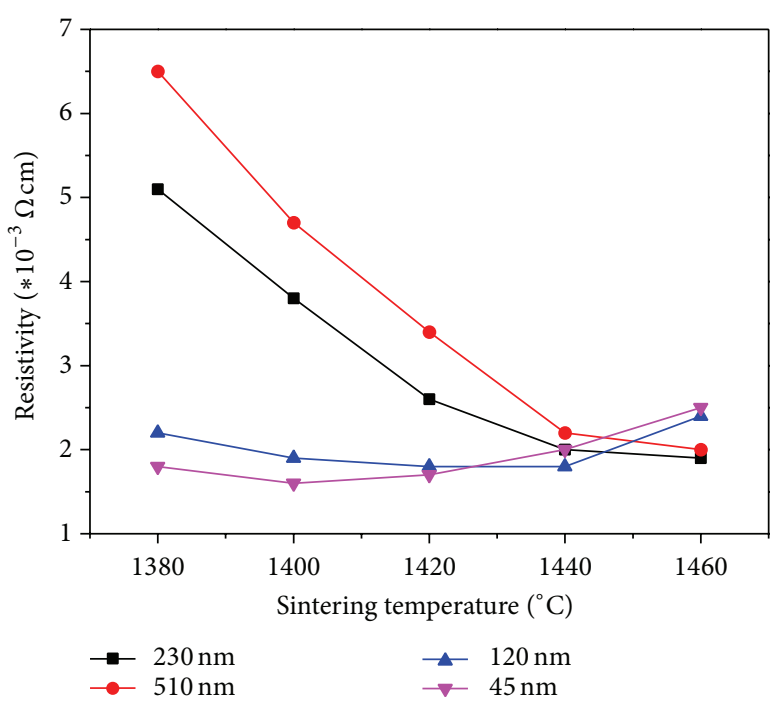

FIGURE 5: Resistivity of the AZO targets sintered at temperatures of $1380,1400,1420,1440$, and $1460^{\circ} \mathrm{C}$.

movement of electrons along the grain boundary. However, when the sintering temperature reached a relatively high value $\left(1440^{\circ} \mathrm{C}\right)$, the elevated internal vapour stress leads to the growth of the pores, which accelerated the scattering of the electrons and decreased the resistivity. Figure 3 shows that 


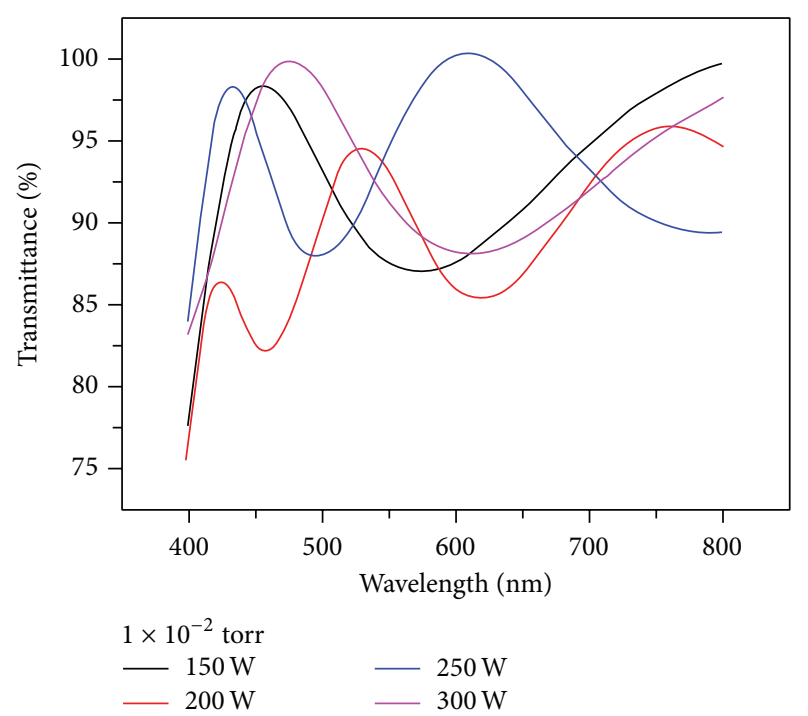

FIGURE 6: Transmittance spectrum for AZO films deposited at different working powers.

TABLE 2: Deposition parameters of the AZO films.

\begin{tabular}{lccccc}
\hline Working power $(\mathrm{W})$ & 100 & 150 & 200 & 250 & 300 \\
\hline Deposition rate $(\AA / \mathrm{sec})$ & 0.047 & 0.191 & 0.27 & 0.62 & 0.97 \\
Deposition time $(\mathrm{min})$ & 1064 & 262 & 185 & 80 & 51 \\
Transmittance $(\%)$ & - & 92.67 & 89.51 & 93.73 & 92.76 \\
Sheet resistance $(\Omega / \mathrm{sq})$ & - & 200.42 & 52.83 & 38.86 & 45.28 \\
\hline
\end{tabular}

the resistivity of the nanometre samples remains at a relatively low standard $(1.6-2.5 \Omega \cdot \mathrm{cm})$ over the entire sintering process, which indicates that $\mathrm{AZO}$ targets with good electrical properties fabricated by nanometre-sized particles could be achieved at a relatively low temperature $\left(1380^{\circ} \mathrm{C}\right)$.

3.4. AZO Film. Table 2 lists the parameters of the AZO films deposited at different working powers. The films were prepared by using the $45 \mathrm{~nm}$ AZO compact sintered at $1420^{\circ} \mathrm{C}$. As shown in Table 2, the transmittance and sheet resistance cannot be tested because of the absence of a complete film when the power is $100 \mathrm{~W}$. As the working power increased, the deposition rate increased but the transmittance changed slightly. Due to the formation of complete film, the sheet resistance decreased from $200.42 \Omega /$ sq to $52.83 \Omega /$ sq. Figure 6 shows the optical transmission spectrum of AZO films deposited at different working powers. The average transmittance of the AZO films prepared at different working powers remained at approximately $90 \%$ in the wavelength range of $400-800 \mathrm{~nm}$. As the working power increased, the average transmittance in the visible region increased slightly and reached a maximum value of $93.73 \%$ at $250 \mathrm{~W}$, which corresponds to the results found in a study by Chen et al. [23]. Additionally, there was obvious interference in the spectrum, which indicates that the surface of the AZO films was smooth and homogeneous.

\section{Conclusions}

(1) The viscosities of AZO slurries with different particle sizes for slip casting were studied. A well-dispersed AZO slurry could be obtained when $1.2 \mathrm{wt} \%$ of the dispersant was added. The viscosity increased slightly with excess dispersant and decreased with increasing particle size. The slurry prepared by micrometre-sized particles was more suitable for slip casting.

(2) The relative density of the AZO targets prepared by nanometre-sized particles was higher than that prepared by the micrometre-sized particles at a lower sintering temperature. The relative density of the nanometre-sized target reached nearly $98 \%$ at $1380^{\circ} \mathrm{C}$ and remained at a high level (97.9-98.2\%) from 1380 to $1420^{\circ} \mathrm{C}$.

(3) The variety of resistivity at different sintering temperatures was comparable with the change of density for the sintered AZO targets. The resistivity values of the nanometre target were much lower and more stable than that of targets prepared by micrometre-sized particles.

(4) Sputtering power had no obvious effect on the transmittance of the AZO film. The average transmittance of the AZO film prepared by nanometre-sized particles reached a maximum value of $93.73 \%$ in the visible region at $250 \mathrm{~W}$.

\section{Competing Interests}

The authors declare that there is no conflict of interests regarding the publication of this paper.

\section{Acknowledgments}

The authors are grateful to financial support from The National High Technology Research and Development Program of China (2012AA03030315).

\section{References}

[1] A. M. R. Senos, M. R. Santos, A. P. Moreira, and J. M. Vieira, "Grain boundary phenomena in the early stages of sintering of MO oxides," in Surfaces and Interfaces of Ceramic Materials, vol. 173, pp. 553-563, Springer, Amsterdam, The Netherlands, 1989.

[2] A. M. R. Senos and J. M. Vieira, "Pore size distribution and particle rearrangement during sintering," in Proceedings of the 3rd European Ceramic Society Conference (ECers '93), vol. 1, pp. 821-826, 1993.

[3] A. M. R. Senos, Sintering kinetics in open porosity stages of zinc oxide [Ph.D. thesis], University of Aveiro, Aveiro, Portugal, 1993.

[4] T. Senda and R. C. Bradt, "Grain growth in sintered $\mathrm{ZnO}$ and $\mathrm{ZnO}-\mathrm{Bi}_{2} \mathrm{O}_{3}$ ceramics," Journal of the American Ceramic Society, vol. 73, no. 1, pp. 106-114, 1990.

[5] M. Sida, S.-Y. Chun, N. Wakiya, K. Shinozaki, and N. Mizutani, "Effect of the sintering temperature and atmosphere on the grain growth and grain boundary phase formation of Pr-doped $\mathrm{ZnO}$ varistor," Journal of the Ceramic Society of Japan, vol. 104, no. 1, pp. 44-48, 1996.

[6] B. Chiou and M. Chung, "Effect of copper additive on the microstructure and electrical properties of polycrystalline zinc oxide," Journal of the American Ceramic Society, vol. 75, no. 12, pp. 3363-3368, 1992. 
[7] J. Han, A. M. R. Senos, and P. Q. Mantas, "Nonisothermal sintering of Mn doped ZnO," Journal of the European Ceramic Society, vol. 19, no. 6-7, pp. 1003-1006, 1999.

[8] J. Han, P. Q. Mantas, and A. M. R. Senos, "Grain growth in Mndoped ZnO," Journal of the European Ceramic Society, vol. 20, no. 16, pp. 2753-2758, 2000.

[9] T. Minami, "Substitution of transparent conducting oxide thin films for indium tin oxide transparent electrode applications," Thin Solid Films, vol. 516, no. 7, pp. 1314-1321, 2008.

[10] G. Fang, D. Li, and B.-L. Yao, "Fabrication and vacuum annealing of transparent conductive AZO thin films prepared by DC magnetron sputtering," Vacuum, vol. 68, no. 4, pp. 363372, 2002.

[11] R. Cebulla, R. Wendt, and K. Ellmer, "Al-doped zinc oxide films deposited by simultaneous $\mathrm{rf}$ and dc excitation of a magnetron plasma: relationships between plasma parameters and structural and electrical film properties," Journal of Applied Physics, vol. 83, no. 2, pp. 1087-1095, 1998.

[12] S. Yoshioka, F. Oba, R. Huang, I. Tanaka, T. Mizoguchi, and T. Yamamoto, "Atomic structures of supersaturated $\mathrm{ZnO}-\mathrm{Al}_{2} \mathrm{O}_{3}$ solid solutions," Journal of Applied Physics, vol. 103, no. 1, Article ID 014309, 9 pages, 2008.

[13] J. Li, J.-H. Huang, Y.-L. Zhang, Y. Yang, W.-J. Song, and X.-M. $\mathrm{Li}$, "Effects of rapid thermal annealing in different ambients on structural, electrical, and optical properties of $\mathrm{ZnO}$ thin films by sol-gel method," Journal of Electroceramics, vol. 26, no. 1-4, pp. 84-89, 2011.

[14] J. G. Lu, S. Fujita, T. Kawaharamura et al., "Carrier concentration dependence of band gap shift in n-type ZnO:Al films," Journal of Applied Physics, vol. 101, no. 8, Article ID 083705, 2007.

[15] M.-W. Wu, D.-S. Liu, and Y.-H. Su, "The densification, microstructure, and electrical properties of aluminum-doped zinc oxide sputtering target for transparent conductive oxide film," Journal of the European Ceramic Society, vol. 32, no. 12, pp. 3265-3275, 2012.

[16] N. Omura, Y. Hotta, K. Sato, Y. Kinemuchi, S. Kume, and K. Watari, "Fabrication of stable $\mathrm{Al}_{2} \mathrm{O}_{3}$ slurries and dense green bodies using wet jet milling," Journal of the American Ceramic Society, vol. 89, no. 9, pp. 2738-2743, 2006.

[17] J. Tsubaki, M. Kato, M. Miyazawa, T. Kuma, and H. Mori, "The effects of the concentration of a polymer dispersant on apparent viscosity and sedimentation behavior of dense slurries," Chemical Engineering Science, vol. 56, no. 9, pp. 30213026, 2001.

[18] X. Li and Q. Li, "YAG ceramic processed by slip casting via aqueous slurries," Ceramics International, vol. 34, no. 2, pp. 397401, 2008.

[19] T. K. Roy, D. Bhowmick, D. Sanyal, and A. Chakrabarti, "Sintering studies of nano-crystalline zinc oxide," Ceramics International, vol. 34, no. 1, pp. 81-87, 2008.

[20] J. Han, P. Q. Mantas, and A. M. R. Senos, "Densification and grain growth of Al-doped ZnO," Journal of Materials Research, vol. 16, no. 2, pp. 459-468, 2001.

[21] Y. Sun, W. Xiong, C. Li, and L. Yuan, "Effect of dispersant concentration on preparation of an ultrahigh density $\mathrm{ZnO}$ $\mathrm{Al}_{2} \mathrm{O}_{3}$ target by slip casting," Journal of the American Ceramic Society, vol. 92, no. 9, pp. 2168-2171, 2009.

[22] S. J. L. Kang, Sintering: Densification, Grain Growth and Microstructure, Butterworth-Heinemann, 2005.
[23] J. Chen, Y. H. Sun, X. Lv et al., "Preparation and characterization of high-transmittance AZO films using RF magnetron sputtering at room temperature," Applied Surface Science, vol. 317, pp. 1000-1003, 2014. 

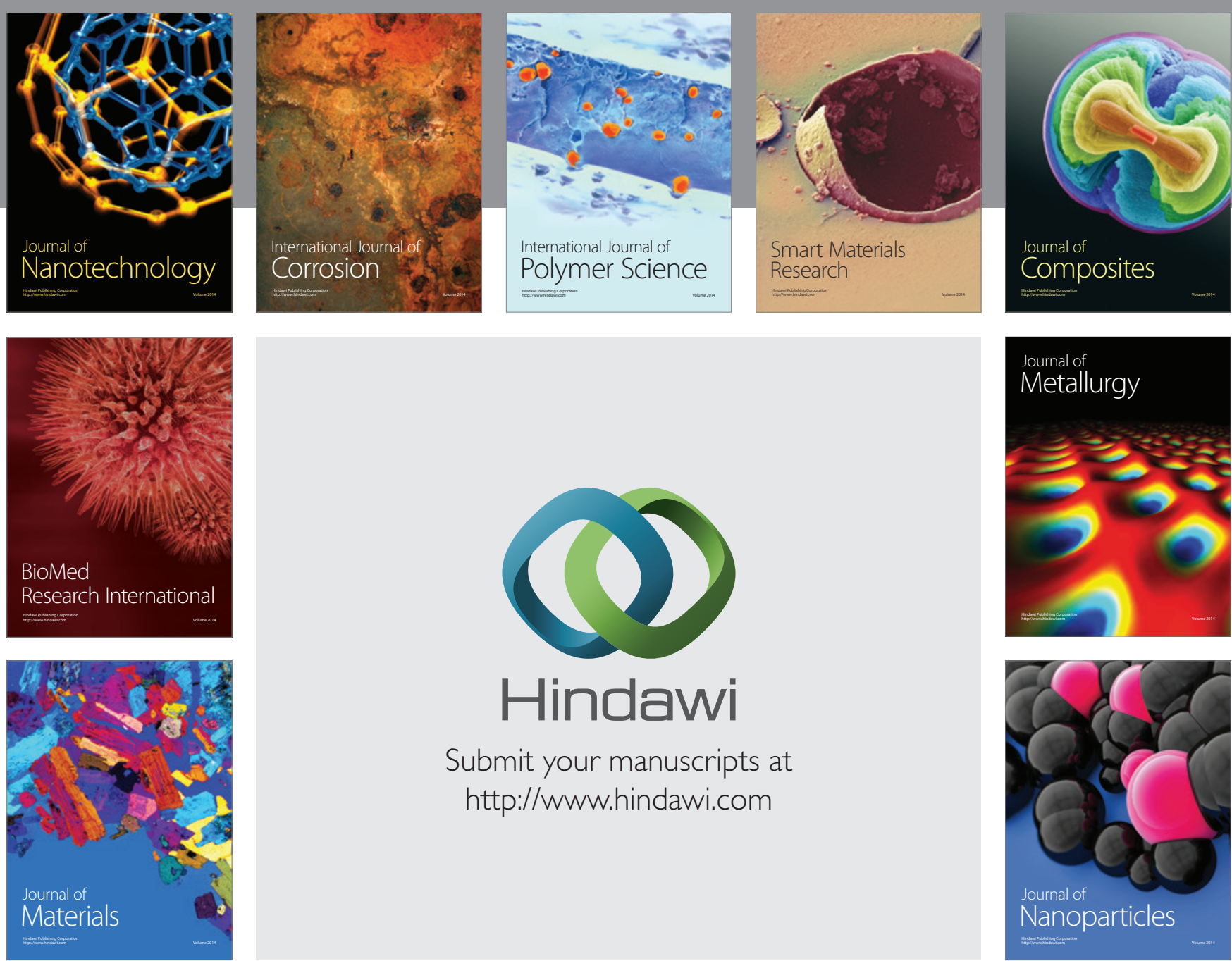

\section{Hindawi}

Submit your manuscripts at

http://www.hindawi.com

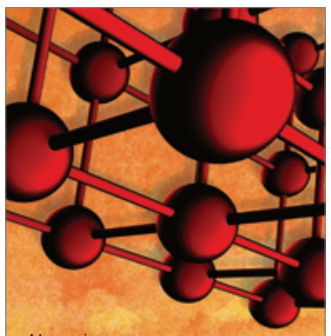

Materials Science and Engineering
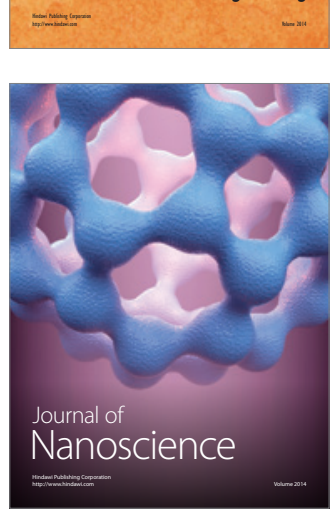
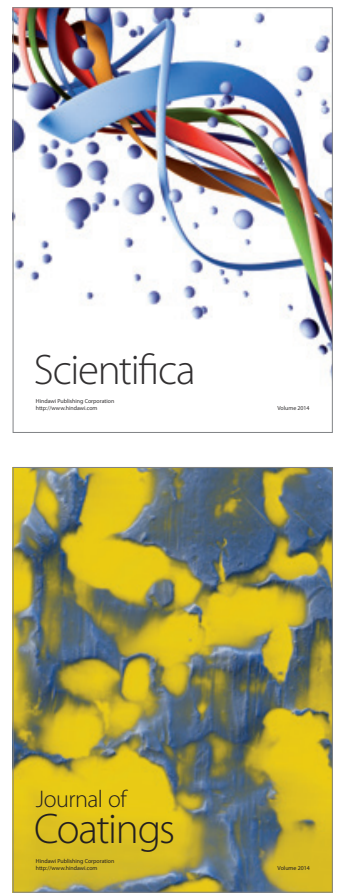
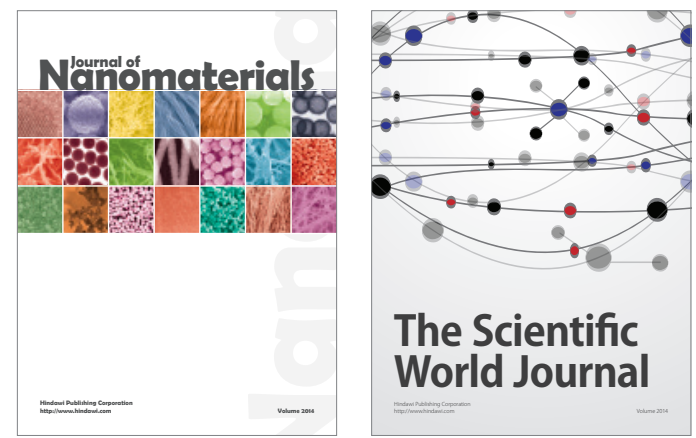

The Scientific World Journal
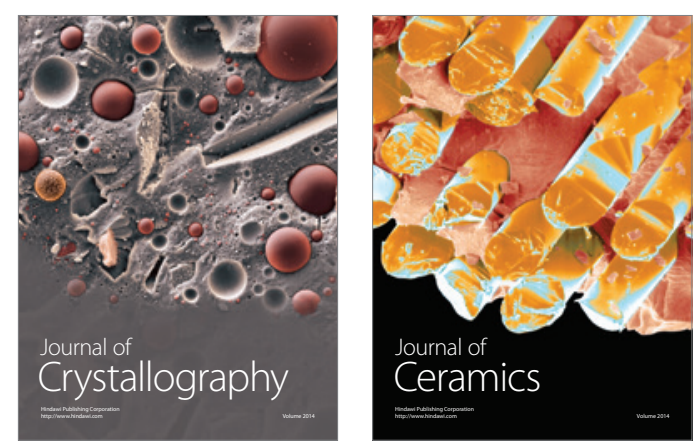
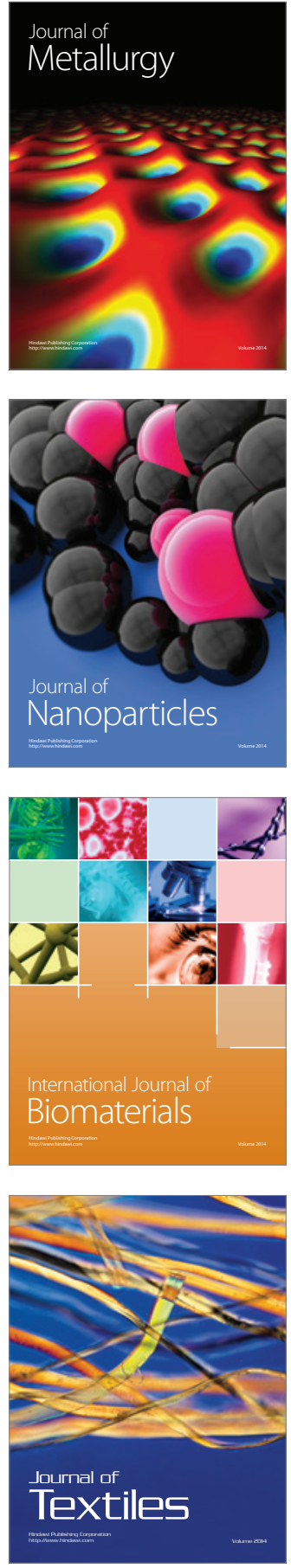